\title{
Flame Entrainment and Its Application to Compartment Fires
}

\author{
BRIAN LATTIMER* \\ Hughes Associates, Inc. \\ 3610 Commerce Drive, Suite 817 \\ Baltimore, MD 21227 USA \\ *currently at Virginia Tech
}

\begin{abstract}
Entrainment into flames is important in predicting the mass flow into the upper-layer of compartment fires where the flame height is similar to or greater than the layer interface height. An analytical model for entrainment into flames was developed based on the simple wetted perimeter approach. The model was validated with existing data and other analytical models for area and line fires located in the open, against a wall, and in a corner. The validated flame entrainment model was integrated into a two-layer compartment fire model and used to predict door flow rates and interface heights with the fire in different locations within the compartment. Predicted door flow rates and interface heights agreed well with compartment fire data from several sources.
\end{abstract}

KEYWORDS: entrainment, flames, door flows

NOMENCLATURE LISTING

\begin{tabular}{|c|c|c|c|}
\hline$A$ & Area $\left(\mathrm{m}^{2}\right)$ & $S$ & Stoichiometric air to fuel mass ratio (- -) \\
\hline$A_{s}$ & $\begin{array}{l}\text { Internal surface area of compartment } \\
\text { including floor }\left(\mathrm{m}^{2}\right)\end{array}$ & $W_{d}$ & Width of door (m) \\
\hline$A_{w, l}$ & $\begin{array}{l}\text { Surface area of walls and floor in contact } \\
\text { with lower-layer }\left(\mathrm{m}^{2}\right)\end{array}$ & $z$ & Elevation above room floor (m) \\
\hline C & Coefficient for MQH Equation & $z_{i}$ & Interface height (m) \\
\hline$C_{d}$ & Door flow coefficient $(0.73)$ & $z_{n}$ & Neutral plane height (m) \\
\hline$C_{p}$ & Specific heat capacity $\left(\mathrm{kJ} / \mathrm{kg}^{-}{ }^{\circ} \mathrm{C}\right)$ & $z_{\text {fire }}$ & Elevation of fire above the floor (m) \\
\hline$C_{p, g}$ & Specific heat capacity of gases $\left(1.0 \mathrm{~kJ} / \mathrm{kg}^{\circ}{ }^{\circ} \mathrm{C}\right)$ & \multicolumn{2}{|r|}{ Greek } \\
\hline$d$ & Characteristic length of fire base (m) & $\chi$ & Radiative fraction of fire (- -) \\
\hline$D$ & Diameter of fire base (m) & $\varepsilon$ & Emissivity (- -) \\
\hline$D_{r}$ & Depth of room (m) & $\gamma$ & Door flow variable defined by Eq. 24 \\
\hline $\mathrm{Fr}$ & Froude number (- -) & $\pi$ & Constant, 3.14159 \\
\hline$f$ & $\begin{array}{l}\text { Number of characteristic lengths for } \\
\text { entrainment (- -) }\end{array}$ & $\theta$ & $\begin{array}{l}\text { Temperature difference term as defined in } \\
\text { Eqs. } 19-23\end{array}$ \\
\hline$g$ & Gravitational constant $\left(9.81 \mathrm{~m} / \mathrm{s}^{2}\right)$ & $\rho$ & Density $\left(\mathrm{kg} / \mathrm{m}^{3}\right)$ \\
\hline$h$ & Enthalpy (kJ/kg) & $\sigma$ & $\begin{array}{l}\text { Stefan-Boltzman Constant } \\
\left(5.67 \times 10^{-11} \mathrm{~kW} / \mathrm{m}^{4}-\mathrm{K}\right)\end{array}$ \\
\hline$h_{c}$ & $\begin{array}{l}\text { Convective heat transfer coefficient } \\
\left(\mathrm{kW} / \mathrm{m}^{2}{ }^{\circ} \mathrm{C}\right)\end{array}$ & $\tau$ & Integration variable for time \\
\hline$H$ & Height (m) & \multicolumn{2}{|c|}{ Subscripts } \\
\hline$H_{d}$ & Height of door (m) & $d$ & Door \\
\hline$\Delta H_{c}$ & Heat of combustion $(\mathrm{kJ} / \mathrm{kg})$ & $e$ & Exiting control volume \\
\hline$k$ & Thermal conductivity $\left(\mathrm{kW} / \mathrm{m}-{ }^{\circ} \mathrm{C}\right)$ & ent & Entrainment into fire \\
\hline$m$ & Mass (kg) & $f$ & Fuel \\
\hline$\dot{m}$ & Mass flow rate(kg/s) & $f l$ & Floor \\
\hline$q^{\prime \prime}$ & Net heat flux onto surface $\left(\mathrm{kW} / \mathrm{m}^{2}\right)$ & $g$ & Gas \\
\hline$Q$ & Heat release rate $(\mathrm{kW})$ & $i$ & Into control volume \\
\hline$Q_{u l}$ & $\begin{array}{l}\text { Convective heat transfer between upper and } \\
\text { lower-layers }(\mathrm{kW})\end{array}$ & l & Lower-layer \\
\hline$Q_{w, l}$ & Convective heat transfer between lower-layer & $n$ & Current time step \\
\hline
\end{tabular}

FIRE SAFETY SCIENCE-PROCEEDINGS OF THE NINTH INTERNATIONAL SYMPOSIUM, pp. 883-894

COPYRIGHT @ 2008 INTERNATIONAL ASSOCIATION FOR FIRE SAFETY SCIENCE / DOI:10.3801/IAFSS.FSS.9-883 




\section{INTRODUCTION}

The majority of research on entrainment into fires has focused on the entrainment into plumes above the height of the flame. Reviews of this research can be found in Refs. [1-3]. These relations are routinely used in smoke control design applications of large spaces (atriums, sporting complexes, etc.) where the flame height is well below the smoke layer interface height [4]. In other applications where the compartment containing the fire may be much smaller, the flame height may be similar to or higher than the interface height of the smoke layer in the space. In addition, fires may be located against surfaces or could be different sizes, which is known to affect the entrainment into the flames [5-8]. Within the flaming region of the fire, researchers have determined that entrainment is not a function of fire heat release rate but is dependent on height and fire diameter [2,8,10,11].

Some research has been performed on measuring entrainment into flames and developing analytical models to predict this entrainment [7-11]. However, these analytical models are restricted to fires in the open and for certain types of fires (e.g., either area or line fires). In addition, there is no general analytical model that can predict the entrainment into flames against surfaces as well as for different types of fires (area, line, burning surfaces, etc.). This paper presents an analytical model to predict entrainment into flames that accounts for the effects of flames against surfaces and different types of fires. Entrainment predicted by the model was validated against existing data and compared with correlations from more complex flame entrainment models developed for specific fire types. The model was then integrated with a two-layer compartment fire model. With the analytical flame entrainment model, the two-layer compartment fire model was able to predict the door flow rate and layer interface height data from several different sources with the fire in different locations within the compartment.

\section{FLAME ENTRAINMENT}

Analytical models for entrainment into the flaming region of a fire in the open have been proposed in Refs. $[1,2,8,10,11,12]$. These models are restricted to particular types of fires (area sources or line fires). Thomas et al. [8] developed a model for entrainment into flames that was a function of the perimeter of the fire base and the height to the two-thirds power, $\mathrm{z}^{2 / 3}$, but not heat release rate as in plume entrainment correlations. Other researchers [2,10,11] have experimentally demonstrated that entrainment into plumes is a function of the fire base and height but not heat release rate. Based on the correlation from Ref. [8], an analytical model was developed for entrainment into flames of a fire in the open,

$$
\dot{m}_{\text {ent }}=1.24 z^{3 / 2} d
$$

where $z$ is the elevation above the base of the fire at which the entrainment is being determined. This is also similar in form to the middle region $(1<z / d<4$ range) of the Delichatsios model [2]. A comparison of the model in Eq. 1 with data [10,11] and correlations from the literature [2,8] is provided in Fig. 1 plotted similar to that proposed by Delichatsios [2]. The model in Eq. 1 provides a more conservative fit to the data in Refs. $[10,11]$ except low in the flame $(z / d<0.7)$. The multiplying coefficient in Eq. 1 is about $25 \%$ higher than that proposed in Ref. [2] and 60\% higher than that proposed in Ref. [8]. Fortuitously, the model in Eq. 1 also provides a good prediction of entrainment into plumes above the fire. This has observation has also been reported by Hinkley [22] using the model proposed by Thomas et al. [8].

Fires against surfaces are known to have less entrainment due to less surface area for entrainment [5-8]. Thomas et al. [8] suggested that entrainment in the flaming region is a function of the wetted perimeter of the fire where entrainment can occur. For a square base fire in the open, the perimeter would be four times the length of one side. Scaling entrainment based on the entrainment perimeter at the base of the fire, a fire 
against a wall has $75 \%$ the perimeter of the fire in the open, a fire in the corner has $50 \%$ the perimeter, and a burning wall has $25 \%$ the perimeter. Based on this scaling, the generalized form of Eq. 1 is

$\dot{m}_{\text {ent }}=0.31 z^{3 / 2} f d$

where, $\quad f=4$ for fire in the open

$f=3$ for fire by a wall

$f=2$ for fire in a corner or line fire in the open

$f=1$ for a burning wall or a line fire against a wall

This analytical model was compared with available data for different types of fires. When no data was available, the analytical model was compared with results from other models that were developed for a specific type of fire.



Fig. 1. Comparison of fire entrainment model with data for fires in the open (symbols) and other correlations that exist in the literature (lines).

For fires in a corner, a comparison of data and analytical model results from Eq. 2 are provided in Fig. 2. The data was from Tran and Janssens [6] from measurements with the fire in the corner of an ISO 9705 room. As reference, the results from the model of Delichatsios [2] for entrainment into flames for a fire in the open are also shown in the figure. With the modification to account for the fire in the corner $(50 \%$ of the entrainment), the correlation provides a good prediction of the entrainment data.

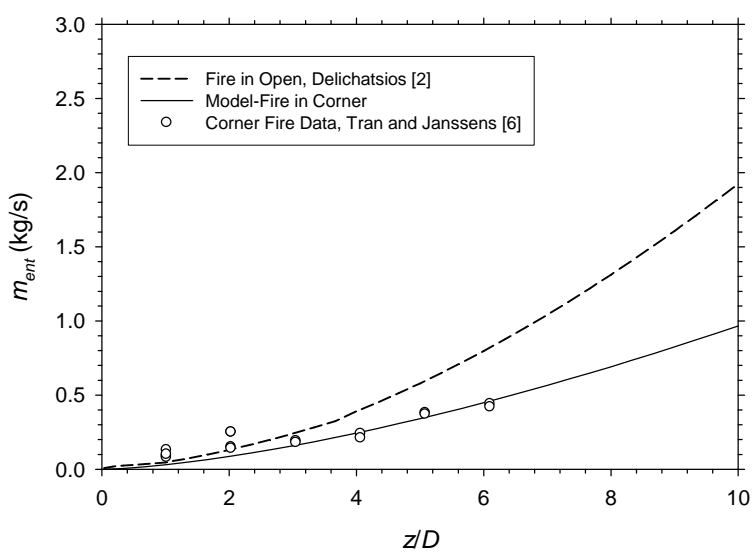

Fig. 2. Comparison of fire entrainment model with data (symbols) for (a) fires in the open and (b) fires in a corner as well as other correlations that exist in the literature (lines). 
Predictions for entrainment into wall fires are provided in Fig. 3. In this figure, the analytical model in Eq. 2 was compared with two other analytical models based on line fires. Quintiere and Grove [13] used plume theory to develop expressions for both the flaming and non-flaming regions of a line fire. In the study by Yuan and Cox [9], a correlation was developed for air entrainment into line fires based on experimental data. The method of images was applied in order to predict wall fire entrainment using the line fire results from these two studies. As a result, the line fire entrainment results from Quintiere and Grove [13] and Yuan and Cox [9] were divided by two to produce the wall fire entrainment results in Fig. 3. Models from these two studies agree well with analytical model results using Eq. 2. The Quintiere and Grove model agrees better with the model in Eq. 2, but the reason for this better agreement is not known.

A comparison of the entrainment rates predicted using Eq. 2 with the fire in different configurations is provided in Fig. 4. For reference, the correlation from Ref. [2] for a fire in the open is also shown. As expected from the correlation, the fire in the open entrains the most while the burning wall entrains the least.

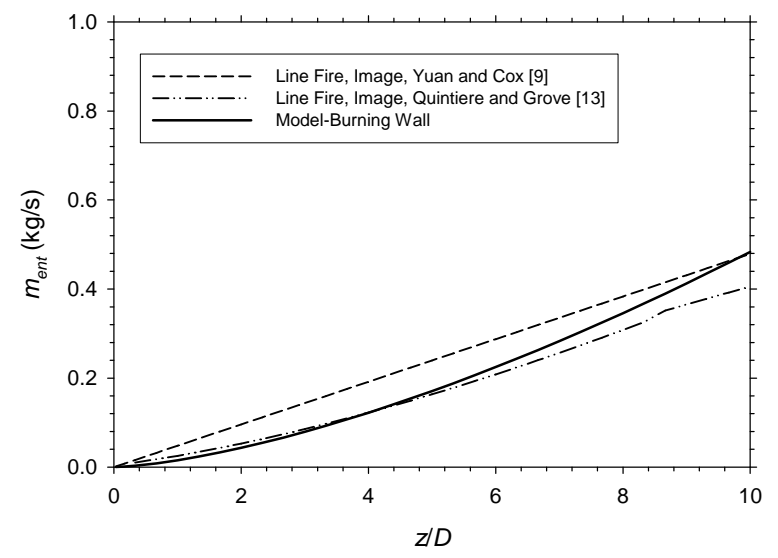

Fig. 3. Comparison of model predictions for a burning wall, $100 \mathrm{~kW}$ and $D=0.30 \mathrm{~m}$ wide, with correlations existing correlations for entrainment into flames of a line fire.

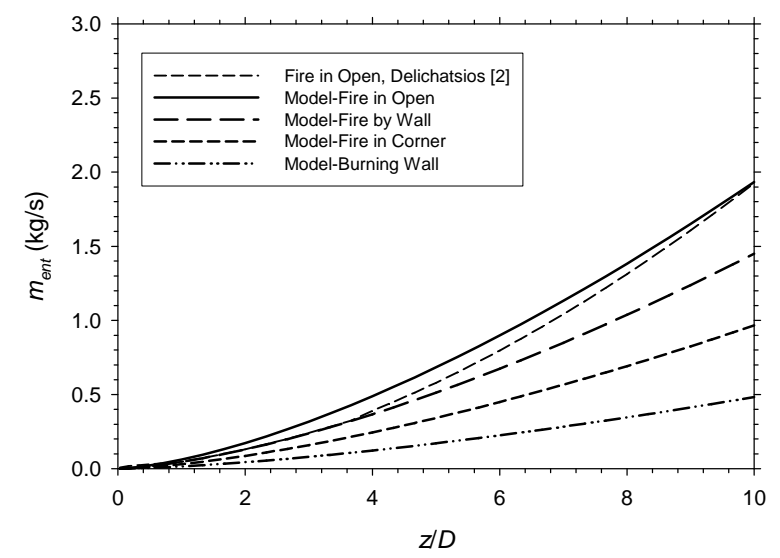

Fig. 4. Predicted entrainment for $100 \mathrm{~kW}$ fire with a $D=0.30 \mathrm{~m}$ with the fire in different locations.

\section{TWO LAYER COMPARTMENT FIRE MODEL}

A two-layer compartment fire model was developed to predict the gas temperature and layer height inside a compartment with a single door opening. As shown in Fig. 5, the two-layer model consists of a cool lower layer and a hot upper-layer that meet at an interface height, $z_{i}$ The compartment is connected to ambient conditions by a door. At the door, the flow is bi-directional with gases flowing out of the compartment above the neutral plane and flowing into the compartment below the neutral plane. The fire can be located in the center of the room, against a wall, or in a corner, and the elevation of the fire above the floor can be 
specified. Mass from the lower layer to the upper-layer is transferred through the fire. Entrainment into the fire below the upper-layer in the room will control where the interface height is inside of the room. For many rooms, the flame height will be similar to or greater than the interface height. As a result, the analytical flame entrainment model developed in the previous section (see Eq. 2) was included in the compartment fire model. Since the model in Eq. 2 provides a reasonable estimate of the entrainment into plumes, this model is expected to be able to predict entrainment even the flame height is just below the interface height. For inclusion in the compartment fire model, the variable $z$ was replaced by the height over which entrainment occurs in the lower layer, $z=\left(z_{i}-z_{\text {fire }}\right)$, where $z_{i}$ is the interface height and $z_{\text {fire }}$ is the elevation of the base of the fire above the compartment floor.

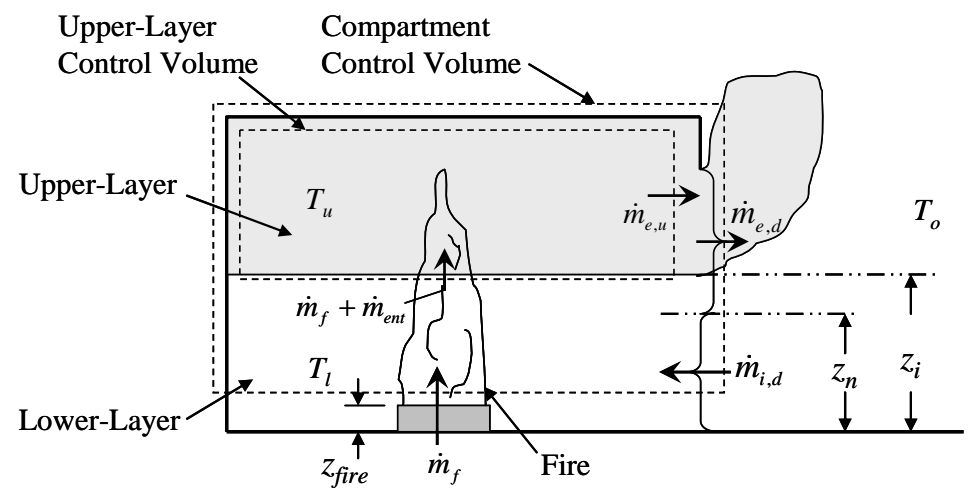

Fig. 5. Two-layer compartment fire model.

\section{Overview of Equations}

The governing equations for the flow in a two-layer model consists of a mass balance on the upper-layer and a mass balance for the entire compartment. The mass balance for the upper-layer is given as

$\dot{m}_{e, u}-\dot{m}_{e n t}-\dot{m}_{f}=0$

while the mass balance at the door is given as

$\dot{m}_{e, d}-\dot{m}_{i, d}-\dot{m}_{f}=0$

Solution of Eq. 3 and Eq. 4 requires calculating the upper and lower-layer temperatures, fuel mass flow rate, mass flow in and out of the compartment, neutral plane, interface height, and entrainment into the fire below the interface height.

The gas temperature was calculated using the correlation developed by McCaffery, Harkleroad, and Quintiere (MQH) equation [14],

$T_{u}=T_{o}\left\{1+C\left[\frac{Q}{T_{o} \rho_{o} C_{p, g} \sqrt{g} A_{d} \sqrt{H_{d}}}\right]^{2 / 3}\left[\frac{A_{s} \sqrt{k_{w} \rho_{w} C_{p, w} / t}}{\rho_{o} C_{p, g} \sqrt{g} A_{d} \sqrt{H_{d}}}\right]^{-1 / 3}\right\}$

where, the total surface area of the compartment is

$A_{s}=2 D_{r} H+2 W H+2 D_{r} W-H_{d} W_{d}$

$\rho_{o}=352.8 / T_{o}$ 
The multiplying constant was varied based on the position of the fire, using $C=1.63$ with the fire in the center of the room and $C=2.2$ with in the corner [15]. For a fire against a wall, a constant between the center and corner values was used, $C=1.92$. The MQH equation was selected for use in the model because of its ease of application in the model, and it provides reasonable results for preflashover scenarios.

No correlations existed for predicting lower-layer temperatures in the compartment; therefore, an energy balance on the lower part of compartment was used to determine the lower layer temperature. The energy balance on the lower-layer with no radiation absorption by the lower-layer gases is ,

$m_{l} C_{p, g} \frac{d T_{l}}{d t}+\dot{m}_{e, l} h_{e, l}-\dot{m}_{i, l} h_{i, l}=Q_{w, l}+Q_{u l}$

where,

$$
\begin{aligned}
& m_{l}=\left(352.8 / T_{l, n-1}\right) A_{f l} z_{i, n-1} \\
& \dot{m}_{e, l} h_{e, l}=\left(\dot{m}_{e, d, l, n-1}+\dot{m}_{e n t, n-1}\right) C_{p, g}\left(T_{l, n-1}-T_{r e f}\right) \\
& \dot{m}_{i, l} h_{i, l}=\dot{m}_{i, d, n-1} C_{p, g}\left(T_{o}-T_{r e f}\right) \\
& Q_{w, l}=A_{w, l} h_{c}\left(T_{w, l, n-1}-T_{l}\right) \\
& Q_{u l}=A_{f l} h_{c}\left(T_{u, n-1}-T_{l}\right) \\
& A_{w, l}=z_{i, n-1}\left(2 D_{r}+2 W\right)+D_{r} W
\end{aligned}
$$

where the convective heat transfer coefficient was taken as $h_{c}=0.015 \mathrm{~kW} / \mathrm{m}^{2}-\mathrm{K}$ and the reference temperature was $T_{\text {ref }}=273 \mathrm{~K}$. Note that at the first time step, current time step values were used in the above calculations except for the lower layer gas and wall temperatures. The methods for determining the mass flow in and out of the lower-layer are discussed below with the door flow equations. Equation 8 was discretized relative to conditions at the previous time step. Substituting Eqs. 9-13 into Eq. 8, an expression for the lower layer temperature was developed. The wall temperature was determined using a heat balance on the wall. The heat transfer through the wall was assumed to behave as a semi-infinite solid with a time varying heat flux imposed on one surface. From Ref. [16], the surface temperature can be calculated by

$$
T_{w, l}=T_{o}+\left(1 / \sqrt{\pi k_{w} \rho_{w} C_{p, w}}\right) \int_{0}^{t} q^{\prime \prime}(\tau) / \sqrt{t-\tau} d \tau
$$

This equation has a point of singularity at the upper integration bound. From Ref. [17], this singularity was removed by dividing the integral into two parts

$$
T_{w, l}=T_{o}+\left(1 / \sqrt{\pi k_{w} \rho_{w} C_{p, w}}\right)\left[\int_{0}^{t_{n-1}} q^{\prime \prime}(\tau) / \sqrt{t-\tau} d \tau+\int_{t_{n-1}}^{t} q^{\prime \prime}(\tau) / \sqrt{t-\tau} d \tau\right]
$$

The heat flux for the increment in time for the second integral is considered constant and equal to the average of the heat flux at the current and previous time steps. As a result, the second integral can be evaluated resulting in the following expression, 
$T_{w, l}=T_{o}+\left(1 / \sqrt{\pi k_{w} \rho_{w} C_{p, w}}\right)\left[\int_{0}^{t_{n-1}} q^{\prime \prime}(\tau) / \sqrt{t-\tau} d \tau+\left[q^{\prime \prime}\left(t_{n-1}\right)-q^{\prime \prime}\left(t_{n}\right)\right] \sqrt{\Delta t}\right]$

The integral in the brackets was evaluated using numerical integration. The time varying surface heat flux was determined using an energy balance on the lower-layer walls,

$q_{w, l}^{\prime \prime}=\frac{\varepsilon_{w} \chi Q\left(z_{i, n-1} / H\right)}{A_{w, l, n-1}}+\frac{\varepsilon_{w} \varepsilon_{u} \sigma T_{u, n-1}^{4} A_{f l}}{A_{w, l, n-1}}-\varepsilon_{w} \sigma T_{w, l, n-1}^{4}-h_{c}\left(T_{w, l, n-1}-T_{l, n-1}\right)$

As seen in this equation, the lower-layer walls are heated by the radiation from the fire plume and the upper-layer gases and walls, which were assumed to be in equilibrium. Heat losses from the walls include re-radiation from the surface and convective cooling from the lower-layer gases. The radiation from the fire was assumed to be uniformly distributed throughout the compartment; therefore, the radiation fraction of the fire was taken to scale with the interface height. The heat flux from the upper-layer to the lowerlayer walls was calculated using a view factor of 1.0. This assumes a negligible loss of radiation out of the door and no radiation absorption by the lower-layer gases. Calculations were performed with the radiative fraction of $\chi=0.20$, a wall emissivity of $\varepsilon_{w}=0.90$ and an upper-layer emissivity of $\varepsilon_{l}=0.90$.

The mass flow at the door was determined using equations from Ref [18]. In this paper, the general mass flow equations for flow through a door were used to derive mass flow expressions for a two layer model. For this, the following notation was applied

$$
\begin{aligned}
& \theta_{\text {ol }}=\left(1 / T_{o}\right)\left[\left(1 / T_{o}\right)-\left(1 / T_{l}\right)\right] \\
& \theta_{\text {ou }}=\left(1 / T_{o}\right)\left[\left(1 / T_{o}\right)-\left(1 / T_{u}\right)\right] \\
& \theta_{l l}=\left(1 / T_{l}\right)\left[\left(1 / T_{o}\right)-\left(1 / T_{l}\right)\right] \\
& \theta_{u l}=\left(1 / T_{u}\right)\left[\left(1 / T_{o}\right)-\left(1 / T_{l}\right)\right] \\
& \theta_{u u}=\left(1 / T_{u}\right)\left[\left(1 / T_{o}\right)-\left(1 / T_{u}\right)\right] \\
& \gamma=1042 C_{d} W_{d}
\end{aligned}
$$

Based on results from Ref. [19], a door flow coefficient of $C_{d}=0.73$ was used in the validation. Mass flow equations are dependent on the location of the interface height relative to the neutral plane. When the interface height is less than the neutral plane $\left(z_{i}<z_{n}\right)$, the door mass flow equations are

$$
\begin{array}{ll}
\dot{m}_{i, d}=\left(\gamma / \theta_{\text {ol }}\right)\left\{\left[\theta_{\text {ol }} z_{i}+\theta_{o u}\left(z_{n}-z_{i}\right)\right]^{3 / 2}+\left(\theta_{\text {ou }}^{1 / 2} \theta_{o l}-\theta_{\text {ou }}^{3 / 2}\right)\left(z_{n}-z_{i}\right)^{3 / 2}\right\} & T_{l}>T_{o} \\
\dot{m}_{i, d}=\gamma \theta_{o u}^{1 / 2}\left(z_{n}-z_{i}\right)^{1 / 2}\left(z_{n}+z_{i} / 2\right) & T_{l}=T_{o} \\
\dot{m}_{e, d}=\gamma \theta_{u u}^{1 / 2}\left(H_{d}-z_{n}\right)^{3 / 2} &
\end{array}
$$

When the interface height is greater than the neutral plane $\left(z_{i}>z_{n}\right)$, the door mass flow equations are 
$\dot{m}_{i, d}=\gamma \theta_{o l}^{1 / 2} z_{n}^{3 / 2}$

$\dot{m}_{e, d}=\left(\gamma / \theta_{u u}\right)\left\{\left[\theta_{u u}\left(H_{d}-z_{i}\right)+\theta_{u l}\left(z_{i}-z_{n}\right)\right]^{3 / 2}+\left(\theta_{l l}^{1 / 2} \theta_{u u}-\theta_{u l}^{3 / 2}\right)\left(z_{i}-z_{n}\right)^{3 / 2}\right\}$

The mass inflow into the compartment is always assumed to go into the lower-layer,

$\dot{m}_{i, l}=\dot{m}_{i, d}$

Depending on the location of the interface height relative to the neutral plane, the mass flow out of the compartment could be exclusively from the upper-layer or from both the upper and lower layers. With the interface height below or equal to the neutral plane, the mass flow out of the upper-layer layer is equal to the outflow from the door,

$\dot{m}_{e, u}=\dot{m}_{e, d} \quad z_{i} \leq z_{n}$

When the interface height is above the neutral plane, there is outflow from the upper-layer and the lower layer,

$$
\dot{m}_{e, u}+\dot{m}_{e, l}=\dot{m}_{e, d} \quad z_{i}>z_{n}
$$

The total mass flow exiting the compartment is determined using Eq. 29. The fraction of outflow from the upper-layer is determined from Eq. 27 with the interface height subtracted from the door height,

$\dot{m}_{e, u}=\gamma \theta_{u u}^{1 / 2}\left(H_{d}-z_{i}\right)^{3 / 2} \quad z_{i}>z_{n}$

The mass flow out of the lower-layer can be determined using Eq. 29, Eq. 32, and Eq. 33. With all the flow rates at the door known, the mass balance on the upper-layer can be determined using Eq. 3. This requires calculating the mass flow of fuel from the compartment,

$\dot{m}_{f}=Q / \Delta H_{c}$

and knowing the entrainment into the fire up to the interface height from Eq. 2. A FORTRAN program was developed to solve these equations. The program iteratively determines the neutral plane which results in a mass balance within the compartment.

\section{Room Fire Test Validation}

The two-layer model was validated against four different data sets to evaluate the performance of the model under a variety of conditions. This included two sets of data on steady-state conditions during a compartment fire, temporal data for a fire by a wall inside a compartment, and temporal data for an ISO 9705 room/corner test.

Figure 6 contains a comparison of predicted and measured quantities for steady-state compartment tests with the fire at different locations within the compartment. Data included the neutral plane, interface height, upper and lower layer gas temperatures, and door inflow. Tests reported in Ref. [19] were conducted inside a $2.18 \mathrm{~m}$ high, $2.5 \mathrm{~m}$ wide, 2.5 deep compartment with a $1.83 \mathrm{~m}$ high door of widths varying from $0.24 \mathrm{~m}$ to $0.99 \mathrm{~m}$. Fires were from a $0.30 \mathrm{~m}$ in diameter propane burner flush with the floor. Heat release rates ranged from $63 \mathrm{~kW}$ to $158 \mathrm{~kW}$. Dembsey et al. [20] conducted tests in a $2.5 \mathrm{~m}$ high, 2.5 $\mathrm{m}$ wide, $3.7 \mathrm{~m}$ deep compartment with a $2.0 \mathrm{~m}$ high, $0.76 \mathrm{~m}$ wide door. Fires were from a $0.60 \mathrm{~m}$ wide, 1.2 $\mathrm{m}$ long propane burner elevated $0.60 \mathrm{~m}$ above the floor. The side length of the burner was taken as the average side length, $D=0.90 \mathrm{~m}$. Heat release rates included in the testing ranged from $330 \mathrm{~kW}$ to $940 \mathrm{~kW}$. Between the two sets of data, the model was validated against small fires inside compartments with small 
gas temperature increase to larger fires that produced flashover type conditions inside the compartment. The model compared well with both sets of data. In the tests, the interface height was measured to be over a region and the stated interface height was typically an average over this region. As a result, the interface height region could vary by $10-50 \%$ of the stated value. Therefore, the predicted interface heights agree even better with experiment than indicated by Fig. 6b. Upper-layer and lower layer gas temperatures are

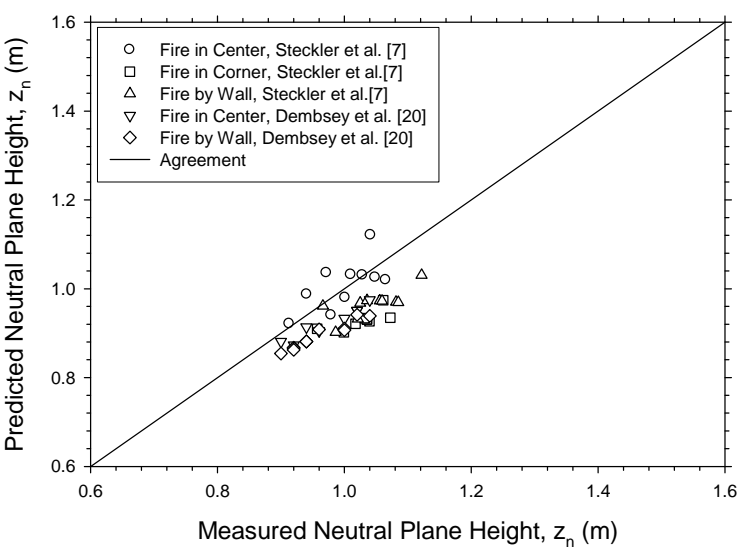

(a)

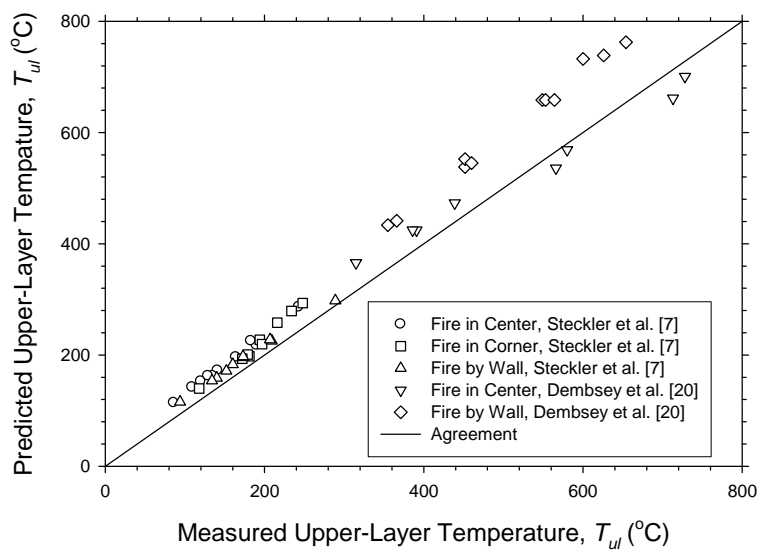

(c)

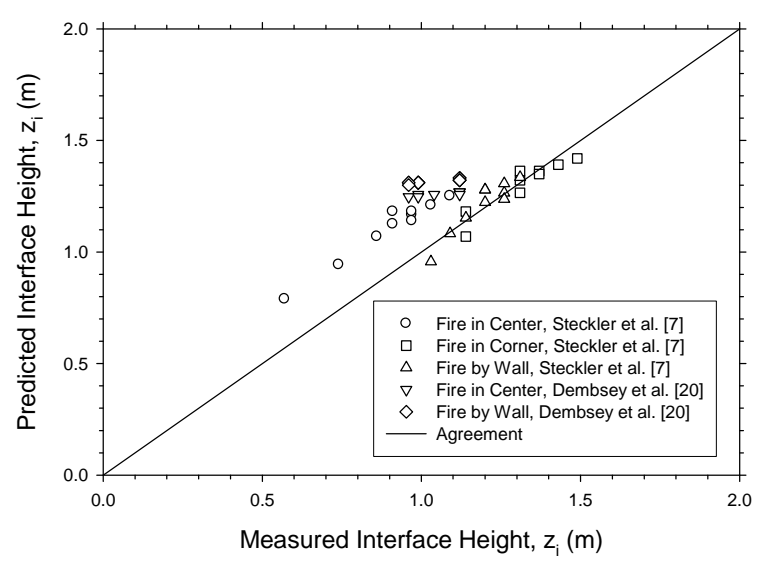

(b)

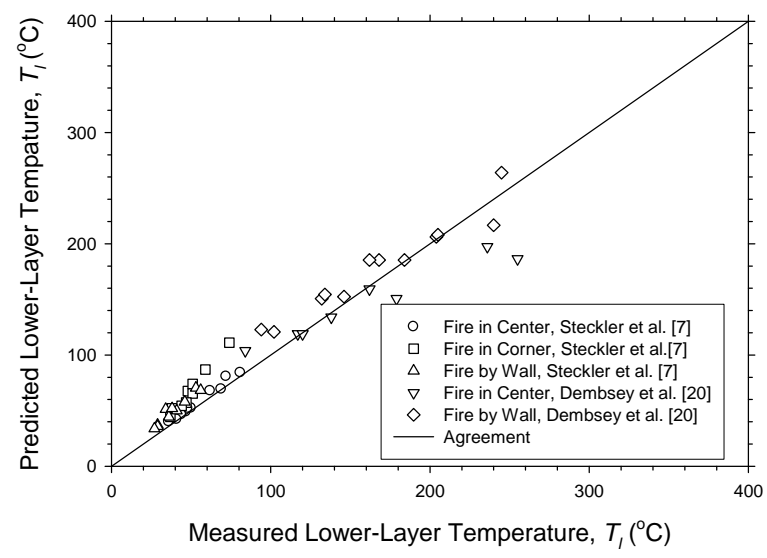

(d)

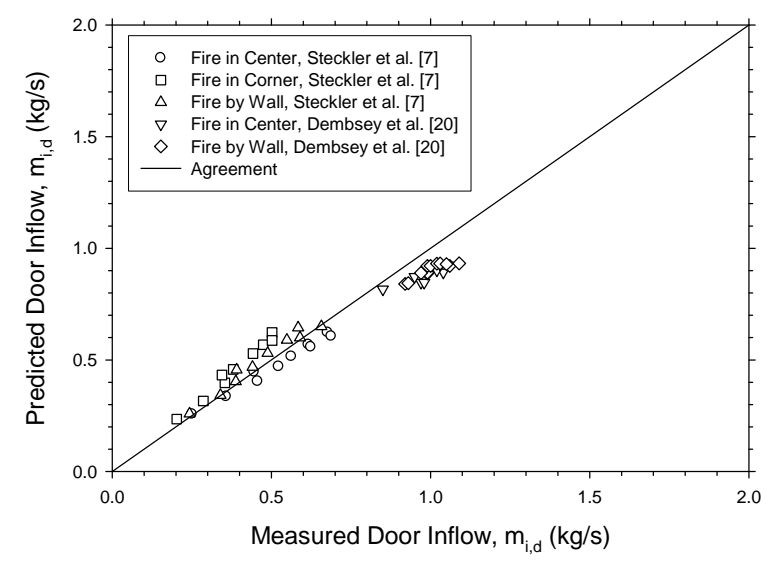

(e)

Fig. 6. Comparison of measured and predicted steady-state quantities for a fire inside a compartment with a two-layer environment. The line in the plots represents exact agreement between the measured and predicted values. 
seen in Figs. 6c and 6d to be generally conservative, while door mass flow rates are seen in Fig. 6e to be on average in agreement with the data.

Time varying predictions of a fire against the back wall of a room are provided in Fig. 7 along with the test data from Ref. [18]. Tests were conducted in a $2.44 \mathrm{~m}$ high, $2.44 \mathrm{~m}$ wide, $3.66 \mathrm{~m}$ deep room with a door $2.03 \mathrm{~m}$ high and $0.76 \mathrm{~m}$ wide. The fire was a $0.30 \mathrm{~m}$ square propane burner $0.30 \mathrm{~m}$ above the floor. The heat release rate shown in Fig. 7a was a step increase from $40 \mathrm{~kW}$ to $160 \mathrm{~kW}$ in 120 seconds and remaining at $160 \mathrm{~kW}$ for the remainder of the 600 second test. Predicted door flows are shown in Fig. 7b to be in good agreement with the data, except early in the test. This is due to not accounting for the transient mass change within the compartment in the mass balance equations. The measured and predicted door flow rates are $30 \%$ less than ventilation limit, $\dot{m}=0.5 A_{d} \sqrt{H_{d}}$. Predicted upper-layer temperatures are shown in Fig. 7c to be in good agreement with the measured temperatures, while predicted lower-layer temperatures are high compared with the data. The predicted interface height and neutral plane agree well with the data except early in the test, which again is due to not accounting for transient changes in mass.



(a)

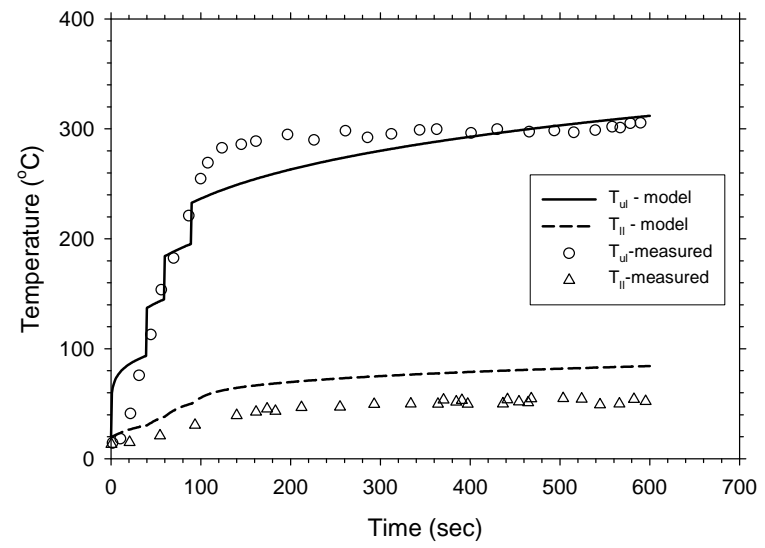

(c)

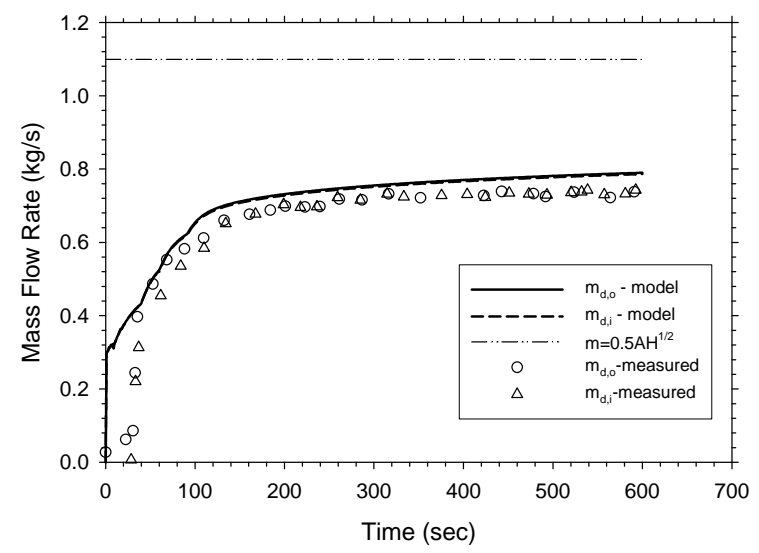

(b)

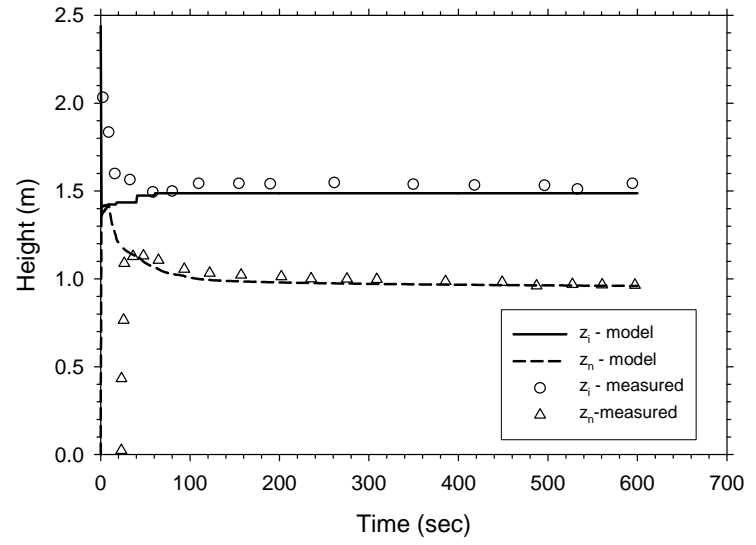

(d)

Fig. 7. Predicted conditions with a step increasing fire against the back wall inside a compartment compared with the data from Ref. [6].

Predictions of the room conditions during an ISO 9705 fire are provided in Fig. 8. The room was $2.44 \mathrm{~m}$ high, $2.44 \mathrm{~m}$ wide and $3.66 \mathrm{~m}$ deep with a $2.0 \mathrm{~m}$ high, $0.80 \mathrm{~m}$ wide door. The fire was a $0.17 \mathrm{~m}$ square propane burner in a back corner of the room and elevated $0.30 \mathrm{~m}$ above the floor. As shown in Fig. 8a, the heat release rate was $100 \mathrm{~kW}$ for 600 seconds and then $300 \mathrm{~kW}$ for the last 600 seconds of the test. Door flow rates are shown in Fig. $8 \mathrm{~b}$ to increase by $50 \%$ when the heat release rate is increased to $300 \mathrm{~kW}$ due to the increase in gas temperatures within the compartment. Predicted temperatures were compared with temperature data from Sorathia et al. [21] in Fig. 8c. Upper-layer and lower layer temperatures agree well with the data. The predicted interface height and neutral plane are provided in Fig. 8d. Based on the temperature data in Fig. 8c, the interface height seems to be reasonable. After the initial part of the 
simulation, the predicted interface height and neutral plane remain relatively constant during the simulation even when the heat release rate is increased to $300 \mathrm{~kW}$ and the mass flow rates into the compartment increase by $50 \%$.

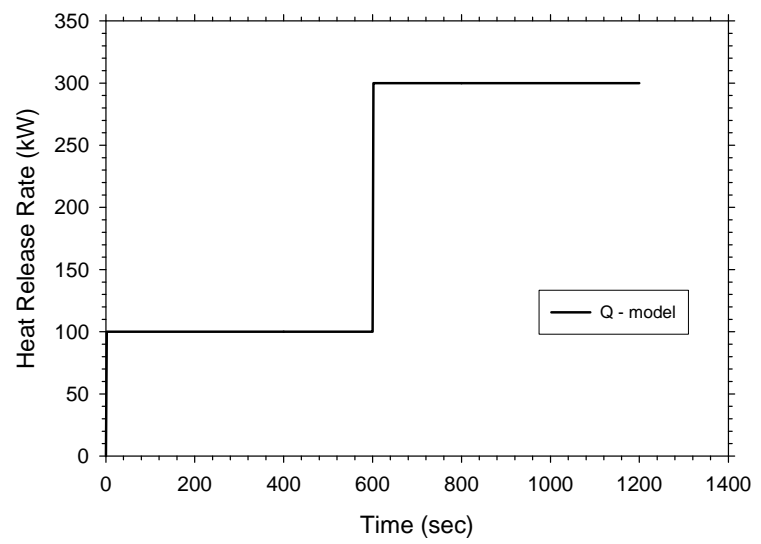

(a)

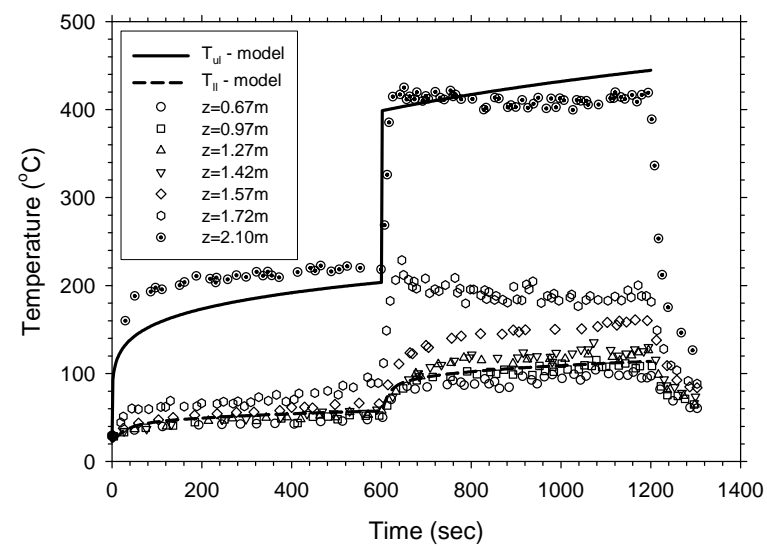

(c)

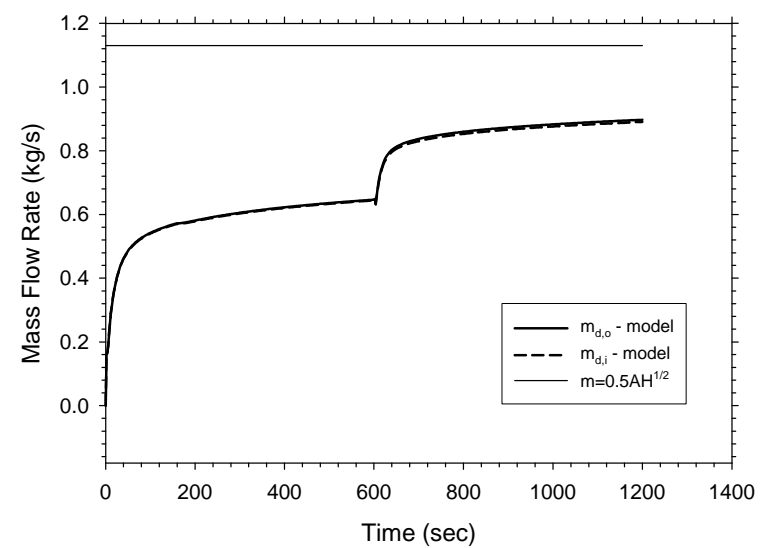

(b)

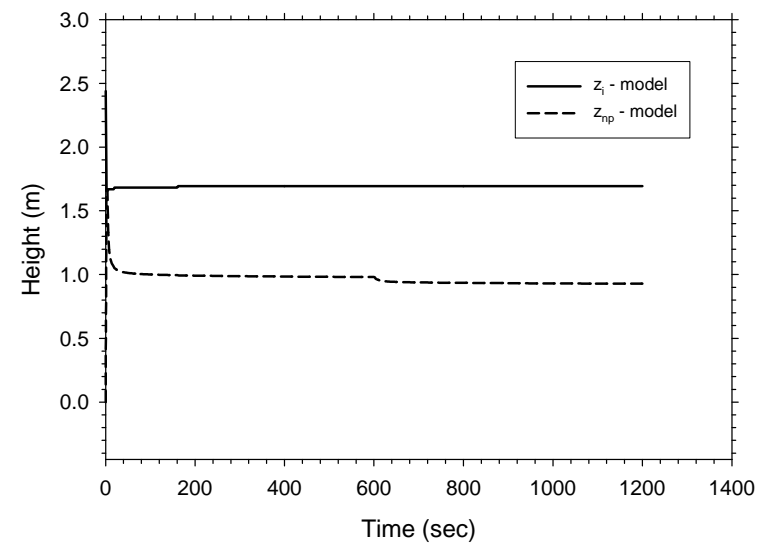

(d)

Fig. 8. Conditions predicted during an ISO 9705 room corner test with a non-combustible wall lining compared with the data of Sorathia et al.[21].

\section{CONCLUSIONS}

An analytical model was developed to predict entrainment into flames using a wetted perimeter approach. The model was validated against available fire entrainment data and predicted entrainment from other more complex models. From this validation, the model was demonstrated to be capable of predicting entrainment into flames in the open or against surfaces and can be applied to area fires, line fires or burning walls. After integrating this flame entrainment model into a two-layer compartment fire model, the compartment fire model was capable of predicting the door flow rates and interface heights measured in compartment fire tests from different sources with fires in different locations within the compartment.

\section{ACKNOWLEDGEMENTS}

The author would like thank Dr. Craig Beyler for the discussions on topics related to this paper.

\section{REFERENCES}

[1] Heskestad, G., "Fire Plumes, Flame Height, and Air Entrainment," The SFPE Handbook of Fire Protection Engineering, Third Edition, Ed. P.J. DiNenno, 2002.

[2] Delichatsios, M., "Air Entrainment into Buoyant Jet Flames and Pool Fires," The SFPE Handbook of Fire Protection Engineering, Second Edition, Ed. P.J. DiNenno, 1995. 
[3] Beyler, C., (1986) “Fire Plumes and Ceiling Jets,” Fire Safety Journal, 11:53-75. doi:10.1016/0379-7112(86)90052-4

[4] NFPA 92B, "Standard for Smoke Management Systems in Malls, Atria, and Large Areas," National Fire Protection Association, Quincy, MA, 2005.

[5] Zukoski, E., Kubota, T., and Cetegan, B., (1981) “Entrainment in Fire Plumes,” Fire Safety Journal, 3(3):107-121. doi:10.1016/0379-7112(81)90037-0.

[6] Tran, H. and Janssens, M., (1993) "Modeling the Burner Source used in the ASTM Room Fire Test," Journal of Fire Protection Engineering, 5(2):53-66. doi:10.1177/104239159300500202.

[7] Steckler, K., Quintiere, J., and Baum, H., "Flow Induced by a Fire in a Compartment," NBSIR 822520, Washington, D.C., 1982, 93p.

[8] Thomas, P., Hinkley, P., Theobald, C., and Sims, D., "Investigations into the Flow of Hot Gases in Roof Venting," Fire Research Technical Paper No. 7, HMSO, London, 1963.

[9] Yuan, L. and Cox, G., (1996) "An Experimental Study of Some Line Fires," Fire Safety Journal, 27:123-139. doi:10.1016/S0379-7112(96)00047-1.

[10] Beyler, C., "Development and Burning of a Layer of Products of Incomplete Combustion Generated by a Buoyant Diffusion Flame," Thesis, Cambridge, 1983.

[11] Cetegen, B., Zukoski, E., and Kubota, T., (1984) "Entrainment in Near and Far Field of Fire Plumes" Combustion and Science Technology, 35:30-331.

[12] Heskestad, G., (1984) "Engineering Relations for Fire Plumes," Fire Safety Journal, 7:25-32. doi:10.1016/0379-7112(84)90005-5.

[13] Quintiere, J. and Grove, B., "Correlations for Fire Plumes," NIST-GCR-98-744, National Institute of Science and Technology, Washington, D.C., 1998.

[14] McCaffrey, B., Quintiere, J., and Harkleroad, M., (1981) "Estimating Room Fire Temperatures and the Likelihood of Flashover Using Fire Test Data Correlations,” Fire Technology, 17(2):98119. doi:10.1007/BF02479583.

[15] Karlsson, B. and Magnusson, S., "Combustible Wall Lining Materials: Numerical Simulation of Room Fire Growth and the Outline of a Reliability Based Classification Procedure," Fire Safety Science, Proceedings of the $3^{\text {rd }}$ International Symposium, Elsevier Applied Science, G. Cox and B. Langford (Eds.), 1991. doi:10.3801/IAFSS.FSS.3-667.

[16] Carslaw and Jaeger, Conduction of Heat in Solids, 2nd Edition, Oxford University Press, London, p. 76, 1959.

[17] Janssens, M., "Fundamental Thermophysical Characteristics of Wood and Their Role in Enclosure Fire Growth,” Dissertation, Univ. of Ghent (Belgium), National Wood Products Association, 1991, 492 p.

[18] Janssens, M. and Tran, H., (1992) "Data Reduction of Room Tests for Zone Model Validation," Journal of Fire Sciences, 10:528-553. doi:10.1177/073490419201000604.

[19] Steckler, K., Quintiere, J., and Baum, H., "Flow Induced by a Fire in a Compartment," NBSIR 822520, Washington, D.C., 1982, 93p.

[20] Dembsey, N., Pagni, P., and Williamson, B., (1995) "Compartment Fire Near-Field Entrainment Measurements," Fire Safety Journal, 24:383-419. doi:10.1016/0379-7112(95)00030-5.

[21] Sorathia, U., Ness, J., Blum, M., Gracik, T., Le, Ahn, Long, G., McFarland, M., and Lattimer, B., "Room Corner (ISO 9705) Fire Test of GRP/Balsa Sandwich Protected with Structo-Gard," NSWCCD-TR-64-2001/15, U.S. Navy, 2001.

[22] Hinkley, P., 1986, "Rates of Production of Hot Gases in Roof Venting,” Fire Safety Journal, Vol. 10, No. 1, pp.57-65. doi:10.1016/0379-7112(86)90032-9. 